\title{
Pattern Recognition in Fast Capitalism: Calling Literary Time on the Theorists of Flux
}

\author{
Paul Taylor
}

\section{Introduction - Dealing with Speed: Flux Theories' Deterritorialization of the Subject}

The message of any medium or technology is the change of scale or pace or pattern that it introduces into human affairs.

(McLuhan [1964] 1995:8) [emphasis added]

\begin{abstract}
There are too many complaints about society having to move fast to keep up with the machine. There is a great advantage in moving fast if you move completely, if social, educational, and recreational changes keep pace. You must change the whole pattern at once and the whole group together-and the people themselves must decide to move.
\end{abstract}

(Margaret Mead Time Magazine 1954 (McLuhan [1964] 1995:28)[emphasis added]

Fully imagined cultural futures were the luxury of another day, one in which 'now' was of some greater duration. For us, things can change so abruptly, so violently, so profoundly, that futures like our grandparents' have insufficient 'now' to stand on. We have no future because our present is too volatile ... We have only risk management. The spinning of the given moment's scenario's. Pattern Recognition. (Gibson 2003:57) [emphasis added]

Marshall McLuhan attributed the profound changes caused by media technologies to the combined impact of the new levels of speed and scale they brought to bear upon our social patterns. Although McLuhan is frequently misappropriated as an optimistic advocate of these technologically mediated changes in scale and pace, a closer reading of his work suggests that, rather than being merely an uncritical endorser, he encourages us to be more suspicious of the social costs of technologically-induced speed. In Vol 1.1. of this journal this suspicion is admirably represented by such articles as those of Goldman, Papson \& Kersey whilst, in contrast, Luke and also Williams frequently risk expressing a contemporary updating of Margaret Mead's fifty year old technological determinism. Various theorists of flux provide us with sophisticated reinterpretations of the empowering possibilities opened up by speed, but ultimately, as with Mead's injunction, they are still asking us to take adaptive action. More gallingly, we are encouraged to embrace willingly this need to adapt even as we are told that the speed of technologically-mediated events impels us to carry it out.

In the final quotation above, we can see how William Gibson, the novelist who gave us cyberspace as a working concept, sounds a valuable note of caution. He portrays the social cost of embracing flux as an empty, anomic, commodified existence lived in an unreflexive, eternal now. Volatility replaces properly thought out social responses so that all we are left with is a reactive ability to recognize social patterns we no longer control. The purpose of this paper is to interrogate fiction as a resource that offers a corrective balance to those who would too readily advocate going with the flow of fast capitalism, a widespread theoretical tendency henceforth referred to as flux theory. It is true that speed creates opportunities as well as problems, but unlike management consultants who can make a quick buck from putting such commonplaces into a power point presentation, theorists, at least critical ones, should not hesitate from delivering the pessimistic conclusion that the problems may consistently outweigh the opportunities if this is what the evidence does in fact suggest. Such critical pessimism is increasingly unpalatable within mainstream 
academic discourse but it at least avoids swallowing, hook, line and sinker the speed-based ideological manipulations of capitalism as Žižek points out in a similar context: 'The target of critique here involves those aspects of Deleuzianism that, while masquerading as radical chic, effectively transform Deleuze into an ideologist of today's "digital capitalism” (Žižek 2004: xii)

It should be emphasized at this early stage that such pessimism is not a position taken in order merely to provoke. In my work to date I have pursued in detail the various positive forms of oppositional potential that reside within fast capitalism with regard to hacking, hacktivism and Open Source software (see Taylor 1998, 1999, Jordan and Taylor 2004, and Harris and Taylor 2005). What this work demonstrates, however, is that the large body of enthusiastic theorists of flux consistently overestimate the relative significance of such otherwise noble attempts to imaginatively re-orientate the Establishment's technology for more humane purposes. Recognizing the risk that, "the high-speed technological fascination that is characteristic of the postmodern condition can be read ... as a celebration of celebratory capitulation by intellectuals to the new information technology cultures" (Ross 1991: 99), Andrew Ross advocates that theorists learn from the oppositional strategies of the technologically literate:

If there is a challenge here for cultural critics, it might be the commitment to making our knowledge about technoculture into something like a hacker's knowledge, capable of penetrating existing systems of rationality that might otherwise be seen as infallible; a hacker's knowledge, capable of reskilling and, therefore of rewriting, the cultural programs and reprogramming the social values that make room for new technologies; a hacker's knowledge, capable also of generating new popular romances around the alternative uses of human ingenuity. (Ross 1991: 100)

The problem with this call is that "new popular romances" tend to be recuperated for the capitalist purposes that are far from romantic. Contra Ross, the history of hacking has shown that its knowledge was all too readily co-opted by a capitalism fast enough to recuperate oppositional techniques (see Taylor 1998 \& 2005). Hackers were vulnerable to such a reversal and their eventual fate as microserfs because they were always too intimate with the technological object of their affections, celebrators of flux should avoid the same fate in relation to theory.

Excessively enthusiastic theorists of speed thus need a reality check that can ironically be provided by fiction. For example, in Neuromancer, Gibson cogently describes an urban area as "a deliberately unsupervised playground for technology" (Gibson 1984: 19), a useful trope for the way in which fast capitalism needs to grant its citizens a certain amount of freedom only to exploit them better in the long run. If theorists wish to avoid inadvertently becoming cheerleaders for fast capitalism they need to maintain this critical perspective that literature can help provide. Using as a springboard Robert Musil's seminal examination of modernity Der Mann Ohne Eigenschaften (The Man Without Qualities) (1979 [1930]), along with contemporary work dealing specifically with the postmodern world of information technology, I suggest that the notion of pattern recognition can provide an important corrective to excessive optimism. Having recourse to literature in this way may strike some readers as indulgently irrelevant to the key political concerns of the informational world order. On the contrary, I argue that faith in literature's revealing powers as a theoretical resource is one shared by a diverse range of theorists including McLuhan (1995 [1964]), Adorno and Horkheimer (1999 [1944]), Kittler (1997), and Deleuze (1990). Although a theorist of flux whose basic conclusions are rejected in the following sections, Deleuze nevertheless neatly summarizes a key feature of this paper's reliance upon literature with his assertion in The Logic of Sense that artists routinely exhibit clinical and diagnostic attributes to the point that they can be considered: “. . . astonishing diagnosticians or symptomatologists. There is always a great deal of art involved in the grouping of symptoms ... Clinicians who are able to renew a symptomatological picture produce a work of art; conversely, artists are clinicians ... they are clinicians of civilisation ... and it seems moreover, [this] evaluation of symptoms might only be achieved through a novel. " (Deleuze 1990: 237 [emphasis in original])

Without wishing to preemptively reply to criticisms of this paper's reliance upon the insights of fiction, failure to see the wider importance of literature as an instructive perspective on our predicament within fast capitalism can be seen as a generally unacknowledged symptom of the instrumental one-dimensionality of thought that speed creates in its theorists. To counter this symptom, in The Question Concerning Technology (1977), Heidegger opposes the artistically minded concept of poiesis to the brute facticity of technology's enframing properties. The holistic notion of poiesis involves the genuinely open-minded bringing-forth of the world's potentialities as opposed to the challenging-forth of reality with the preconceived categories that accompany technological thinking. Heidegger succinctly points out that the essence of technology is nothing technological. This means, as in McLuhan's explicit and sustained attention to the ways media affect our sense ratios, that technology's ultimate effects go well beyond its immediate physical properties and affect our whole perceptual approach to the world. Its title resonating with 
that of Musil's novel, Marcuse's One Dimensional Man (2002 [1964]) follows a similar theoretical path with his description of how evidence of technology's wider and more subtle social impact is illustrated by the way in which concepts routinely have their substantive meaning eviscerated and then operationalized for more efficient inclusion in pre-ordained structures and systems. Put simply, there is a danger that theories claiming to engage directly with the realities of the information order are in fact guilty of merely reproducing its operational categories in an intellectual context. Unlike the innate sensitivity of novelists to the zeitgeist, speed theorists may obfuscate rather than question the essential nature of fast capitalism.

Even when instrumental theoretical approaches do not confine literature within an aesthetic reservation, free from wider theoretical significance, it remains vulnerable to either obtuse or skillful recuperation. Thus, as with the excessively optimistic appropriation of Marshall McLuhan before him, William Gibson has become known as the original popularizer of the term cyberspace without a more balanced recognition of the admonitions that constantly bubble under the surface of his work. This paper reclaims Gibson's work (in particular the appositely named Pattern Recognition [2003]) to reemphasize the importance of his particularly vivid insights into the particular social patterns caused by the alignment of digital technology and capitalist economics. In doing so I also hope to recover some of the lost irony contained within his oeuvre but consistently overlooked in the salivating excesses of techno-porn (of which Leadbetter [2000] is a particularly egregious example). The notion that Gibson's ironic intent has been lost due to his popular success is perhaps reflected in his tendency to situate his later novels much nearer to the present. This is an act that makes its admonitory quality more difficult to dismiss as the merely futuristic imaginings of science-fiction. In bringing his work into more explicitly contemporary settings, Gibson's fictional perspective still provides him with some critical distance from speed's social effects — a distance that is less easily maintained by uncritical theoretical endorsements of fast capitalism and their over-riding desire to go with the flow. Flux-theorists thus celebrate the decentred, deterritorialized subject of fast capitalism. They are entitled to their creed of speed but their celebration either tends to ignore or pervert the admonitory quality of significant literary accounts of the actual life-world of such a decentred subject.

We shall shortly refer to the useful social science role of literature in more detail, but at this point it is sufficient to point out that in addition to the lost irony of Gibson's oeuvre, such writers as Robert Musil and William Gaddis have also been subject to puzzlingly optimistic interpretations and well-intentioned but ultimately disingenuous reinterpretations. In Musil's much-heralded The Man Without Qualities, for example, notwithstanding the apparent hint in the title, its protagonist Ulrich is interpreted by Jonsson (2000) as an emulatory, prototypical subjectivity for a new age. This is despite the fact that by the end of the novel Ulrich does not provide a clear model with which to compensate for the alarming disintegration of civilization occurring around him. There is just a vague allusion to an ill-defined form of new age consciousness and equally ambiguous hints of an incestuous relationship with his sister. Likewise, in a coincidental pattern of literary criticism, the similarly named Johnston also interprets William Gaddis's work (who in a yet further literary pattern has been confused for William Gibson[1]) as a positive engagement with the new technologically-mediated subject. Flux-theorists seem unable to resist the temptation to indulge in optimistic interpretations of the flux-ridden individual even when confronted by strong evidence in literature that the flows in which such a subject's self-formation takes place are enervating rather than empowering. This evidence abounds in both the eruditely expressed ironies of Gaddis's many layered classical allusions in The Recognitions (1993 [1955]) that impute to contemporary life the quality of a discombobulating simulacra, and the hard to miss (but apparently not impossible) disdain for the spiritual emptiness of capitalism in JR (2003[1976]). Gaddis's negative account of technology's effects culminates in his posthumously published Agape Agape (2005 [2002]), a work that consists of an anguished deathbed jeremiad against the effects of the mediated world upon the traditional lifeworld and how they are underestimated by Walter Benjamin in his Work of Art Essay which is specifically mentioned during the protagonist's stream of ebbing consciousness (ibid: 33).

From such a critical perspective, the new popular romances Ross calls for have indeed been constructed but in the questionable promotion of a heavily mediated subject in a flux-ridden world. It seems clear that literature's aesthetic ironies are seriously in danger of being lost when the individual subject's traditional foundations are enthusiastically replaced by nothing more substantial than the desiring flows of incest and deathbed anger misread as life-affirming catharsis. By contrast, this paper suggests that romantic fictions should be replaced by a less disingenuous recognition of the patterns depicted in fiction that exposes the dark anomic side of fast capitalism's flows. Instead of techno-literacy, and in keeping with Fredric Jameson's idea of a strategy of cognitive mapping with which to orientate ourselves, it reasserts the importance of an old-fashioned literacy, one that is capable of revealing the alienated aspects of the lived-in, phenomenological and ontological nature of fast capitalism's social patterns. 
Without the corrective balance of the literary aesthetic, flux theory is at best a theoretical conceit, and at worst, what Jameson terms a blank parody_-samplings taken from an overpowering informational zeitgeist that have no deeper, underlying value beyond their tautological justification as acts of sampling.

\section{| The im/materiality of flux: the vexed question of the general and the particular}

Two particularly important issues that arise from a critical consideration of fast capitalism's flux are:

1. The consistency with which capitalism's flows overwhelm rather than empower.

2. What constitutes evidence of such consistency.

1. The question as to whether there is a consistent element to the negative, dis-empowering outcomes of fast capitalism is a troublesome one. It relates to the highly complex nature of the capitalist system as just that, a systemic totality[2]. Theorists tend to be split between those who emphasize how capitalism's systemic properties work to evacuate the properties of individuality or particularity and those who prefer to emphasize the opportunities for the expression of particularity within its flows and flux. Those who assert the need to conceptualize the systemic totality would include figures from the Western Marxist tradition such as Adorno. He doggedly highlights advanced capitalism's tendency to make the general and the particular interchangeable in a process of abstraction consistently subordinated to the ultimate advantage of a culture industry that thrives upon the homogeneity and standardization that such interchangeability implies. There is a rhetoric of individuality within capitalism, but it is merely a rhetoric that consumers willingly delude themselves with as they perversely express their individuality by consuming commodities also produced for millions of other "individuals".

This is a theme that can be approached through various writers. In History and Class Consciousness (1968: 1922), Lukács identifies the process as a negative, alienating development with his notion of reification, a direct development of Marx's concept of commodity fetishization. Benjamin (1935), by contrast, recognized the process whereby particularity is reduced and abstraction increased but, in what has proved to be a trend amongst later theorists of fast capitalism, he endeavored to put an optimistic gloss upon the situation. He argues that the specific aura of an event is evacuated (pumped, as he puts it "like water from a sinking ship") by its mechanical reproduction, but this opens up new opportunities for the masses. The division between Adorno/Lukács and Benjamin is replayed in more contemporary times. Deleuze (1992) [3], for example, embraces the schizoid possibilities to be enjoyed by the deterritorialized individual (redefined as the dividual) for whom desire and difference become the new guiding principles within fast capitalism's flows. Implicit in Baudrillard's work, by contrast, is a keen awareness of the loss incurred by such deterritorialization. Human beings are freed up only to partake in a highly mediated umbilical limbo of self-referential screens (Baudrillard 2005). What unites the flux-theorists, is their belief that the traditional Cartesian individual who faces an external totality has been fatally undermined and that, à la Mead, we need to adapt to the new social patterns that result.

Due to the speed of technologically-mediated social change, political subjects who previously had a clear view of the social forces devoted to their disempowerment may now be struggling to peer through the mist but this paper highlights the need to at least wipe our spectacles once in a while, or at the very least, not celebrate the mist. Those on the right of the political spectrum have an obvious affinity for fast capitalism as an impressive sign of commodity culture's rude vitality-its creative gales of destruction. However, in a manner that is similar to the accommodative tendencies of cultural populist theories devised to find positive features in the manipulations of an ever more sophisticated culture industry, similarly, flux-theorists seem unduly willing to make a virtue out of the necessity to accommodate to rapid change. For example, Luke (Fast Capitalism Vol 1.1) provides a good overview of theorists who view quasipolitics unironically, as a concept to work with, rather than an apt description of the technology-sponsored evacuation of substantive political issues. Quasipolitics thus refers to the way in which the level of technological mediation of society has created new forms of politics at a micro-level in a manner similar to Foucault's bio-power (1998). Whilst figures such as Hardt and Negri (2000 \& 2005) have at least attempted to argue that this corporate invasion of cultural life creates oppositional possibilities, flux-optimists seem more concerned with re-describing the corporate takeover as socially beneficial in and of itself so that: "There has been in this respect what one can only characterize as a pervasive failure of political nerve, and in some cases an accelerating, sometimes squalid process of accommodation by sectors of the left to the priorities of a capitalist politics". (Eagleton 1990: 6) 
Instead of connoting passivity, "going with the flow" now seems to have to have assumed the status of a political strategy - albeit one attuned to fast means as an end in themselves rather than a more radical political telos.

2. What constitutes evidence of such regularity? What unites theorists with otherwise radically different perspectives about fast capitalism is the way in which they share a focus upon the relationship between the material and the immaterial, a tension I have previously discussed in detail in terms of im/materiality (Taylor and Harris 2005). They either welcome the conflation of the material and the abstract or they stubbornly insist that the distinction remains an important one. It is a tension that literature is well-placed to illuminate, grounded as it is in the realm of the aesthetic, a realm intrinsically positioned to be a powerful mode of inquiry into the dynamic relationship between things and thoughts, objects and representations, sensuality and abstract thought. The novelists examined below help to refocus our attention upon the im/material. Fiction is shown to provide particularly useful insights into the productive tension between the general and particular that fast capitalism tends to drown out with the much simpler one dimensional phenomenon of speed-induced flux. Literature's aesthetic makes it a valuable non-instrumental mode of thought with which to escape such one dimensionality: "Nothing could be more disabled than a ruling rationality which can know nothing beyond its own concepts ... aesthetic cognition mediates between the generalities of reason and the particulars of sense." (Eagleton 1990: 14 \& 15) Rather than giving into the temptations of flux theory: "The indissoluble must be brought into its own in concepts, not subsumed under the an abstract idea in that generalized barter of the mind which mirrors the equalizing exchanges of the market place." (ibid: 345) Those theorists who seek to ground the notion of the subject in deterritorialized flows risk merely providing intellectual ex post facto justifications of fast capitalism's project.

In literature: 'the hidden irrationality of a rationalized society is brought to light; for art is a 'rational' end in itself, whereas capitalism is irrationally so. Art ... might thus be said to represent an arational reason confronting an irrational rationality ... the process by which rationality criticizes itself without being able to overcome itself.' (ibid: 351) Thus, aesthetic sensibility should not be seen as a substitute for rational theories but a complementary resource with which to plug its gaps: 'There can be no question ... of aestheticizing philosophy in the sense of reducing cognition to intuition, since art ... is itself in its peculiar sort of way a form of rationality. Where theory is to be aestheticized is in its approach to the particular; art does not exactly oust systematic thought, but furnishes it with a model of sensuous receptivity to the specific.' (ibid: 361) The novelists explored here provide a valuable corrective to flux theory by evocatively and sensuously expressing the particularity of the phenomenological experience that is fast capitalism by describing it more accurately than theory can alone. Most importantly, they recognize the social pattern of the speed-based forces arrayed against those social groups seeking to use advanced technologies for noncapitalist purposes.

\title{
| Living and dying in flux-the flâneur and cyberpunk
}

\begin{abstract}
The flâneur ... is an image of movement through the social space of modernity ... The flâneur is a multi-layered palimpsest that enables us to 'move' from real products of modernity, like commodification and leisured patriarchy, through the practical organisation of space and its negotiation by inhabitants of a city, to a critical appreciation of the state of modernity and its erosion into the post- ... (Jenks 1995: 149)
\end{abstract}

The rapid urbanization of the Industrial Revolution brought with it profound social flux. Within this flux, Charles Baudelaire described the urban wanderings of the flâneur, a mid 19th Century quasi-fictional Parisian figure who can be conceived of as a short-lived personification/imaginative representation of the role soon to be taken over by the camera's lens. The flâneur was a man in the crowd but not of the crowd, he was a dandyish figure with enough time on his hands to observe the constant motion of the vibrant city that passed him by as an impartial spectator. This elegant bystander viewed the cityscape as a mysterious code to be deciphered and the gaze with which he observed these scenes were immortalised in various Impressionist paintings. In his Painter of Modern Life, Baudelaire famously elaborated upon the historical epoch the flâneur was witnessing: "By 'modernity' I mean the ephemeral, the fugitive, the contingent". (Baudelaire 2003: 12) The experience of the flâneur and his perambulations amidst the rapid social change of 19th Century Paris serve as a usefully illustrative precursor of the increasingly fragmented and culturally dislocated nature of the social environment within fast capitalism. The flâneur provides an interesting trope for the themes of this paper, because he (and the flâneur 's gaze was invariably a male one) and his 
encounter with the rapidly speeding up city represents an emblematic confrontation with the socially disorientating consequences of modernity that precedes later conceptualizations of flux. Like the flâneur, Edgar Allan Poe's 'Man of the Crowd' (1992 [1850]) wishes to be part of the urban throng and for him, like the later hacker/cyberpunk, 'curiosity has become a fatal, irresistible passion.' (cited in Frisby 1983: 17) It is important to emphasize here that what unites the flâneur and cyberpunk as the prototypical figures of modernity and postmodernity, respectively, is curiosity for the new social flows - not human feeling for fellow citizens. The traditional aesthetic's human-centred mediation between the particular and the general is sublimated here into an individual's solipsistic appreciation of fast capitalism's new abstractly systemic totalities.

A rapidly changing Nineteenth Century Paris is thus for the flâneur what the Matrix is for the cyberpunk:

The crowd is his element, as the air is that of birds and water of fishes. His passion and his profession are to become one flesh with the crowd. For the perfect flâneur, for the passionate spectator, it is an immense joy set up house in the heart of the multitude, amid the ebb \& flow of movement, in the midst of the fugitive $\&$ the infinite. To be away from home and yet to feel oneself everywhere at home; to see the world, and yet to remain hidden from the world ... the lover of universal life enters into the crowd as if it were an immense reservoir of electrical energy. (Baudelaire 2003: 9-10 [emphasis added])

Whilst the vestigial manifestations of urban spatialization provided the flâneur with fodder for his curiosity and entertainment, the onward march of capitalist modernity proved too rapid for the survival of the idly strolling dandy. As the nineteenth century progressed, the flâneur increasingly lost his aura of detached superiority and carefree flippancy. In Balzac's portrayal, for example, the flâneur is said to become: 'a truly hapless soul, whom the city overwhelms rather than fascinates. Far from empowering the walker in the street, the altered urban context disables the individual. Distance and inactivity no longer connote superiority to the milieu, but suggest quite the oppositeestrangement, alienation, anomie.' (Ferguson 1994: 33) In Robert Musil's The Man Without Qualities, this inexorable speeding up of flow has fatal implications for other forms of social life. This is dramatically embodied in the truck that knocks down and kills the flâneur -like figure of a pedestrian in the rapidly urbanizing city of Vienna. This pedestrian rather literally fails to go with a flow in which:

\begin{abstract}
Motor-cars came shooting out of deep, narrow streets into the shallows of bright squares. Dark patches of pedestrian bustle formed into cloudy streams. Where stronger lines of speed transected their loose-woven hurrying, they clotted up-only to trickle on all the faster then and after a few ripples regain their regular pulse-beat ... the general movement pulsed through the streets ... Like all big cities, it consisted of irregularity, change, sliding forward, not keeping in step, collision of things and affairs, and fathomless points of silence in between, of paved ways and wilderness, of one great rhythmic throb and the perpetual discord and dislocation of all opposing rhythms, and as a whole resembled a seething, bubbling fluid in a vessel consisting of the solid material of buildings, laws, regulations, and historical traditions. (Musil 1979: 3 \& 4)
\end{abstract}

In a manner frequently used in cyberpunk fiction, the human and biological are here counterpoised with the technological and its inhuman movement. The geometric vectors of speed transect the more organic movements of the crowd to create a bubbling vessel that resonates with Marx's famous description of capitalist environment as one in which 'all that's solid melts into air'. To stay alive, people must submit themselves totally to the movement and bustle of the 'cloudy streams'. Movement is equated by Musil with the heartbeat of life and a lack of motion implies the danger of a blood clot. This portrayal of the need for an adaptive response to a new social pattern of speed returns us to Margaret Mead's injunction at the start of this article and it is a central element of the cyberpunk genre's message, the full irony of which flux-theorists consistently overlook.

Futuristic flu or retro-futuristic chronosemiitis are the somewhat tongue-in-cheek phrases used by Istvan CsisceryRonay to describe the sense of dislocation that accompanies the advent of such 'speed-up' (see Taylor 2001). The 'now' seems almost instantaneously and anachronistically redundant whilst the future is never quite within reach. Futuristic flu is cyberpunk's distinguishing leitmotif as it takes the accelerated socio-technical change of the industrial revolution to 'warp-speed' levels. 'Night City was like a deranged experiment in social Darwinism, designed by a bored researcher who kept one thumb permanently on the fast-forward button.' (Gibson 1984:14). 'Strange euphoria' (Gibson ibid: 19) is felt negotiating both the 'dance of biz' in the streets and its simulated informational form found in the matrix. The rapid tempo of the dance is such that informational immersion is a sine qua non of survival and requires that you: 'throw yourself into a highspeed drift and skid.' (Gibson ibid: 26) Frenetic activity is the background noise of everyday existence and there is a similar sentiment to Musil's notion of the clot: 'Stop hustling and you sank without a trace ... Biz here was a constant subliminal hum.' (Gibson ibid: 14) Life takes on the aspect of a feral fight to survive by means of the constant movement Musil highlights in a nascent modernity that 
preceeded fast capitalism in full flow: 'To stand still ...is like stopping swimming for a shark. You sink to the bottom, and can't stop moving again.' (Smith 1996: 202). Whilst such descriptions, in addition to Musil's dead pedestrian, vividly evoke the urgency of the need to adapt to the flow, they do not provide much of an insight into any inherent worth of such flux. Like the commodity form to which fast capitalism's flows are ultimately subordinated, flows appear to be their own tautological justification.

Prefiguring Morse (1998) and Bauman's (2000) emphasis upon the liquidity of the contemporary experience, Simmel's overall sociological project can be seen as an examination of the cost to the individual and wider society of this environment in which 'all that is solid melts into air'. Frisby argues that Simmel's work 'is located within the context of a permanent and accelerating opposition between subjective and objective culture.' (Frisby 1986: 41) In Simmel's Uber sociale Differenzierung (1890), for example, he argues that 'the increased externalisation of life that has come about, with regard to the preponderance that the technical side of life has obtained over its inner side, over its personal values'. (cited in Frisby 1986: 42). Frisby succinctly summarizes the central effect of a pervasive sense of fluidity: 'The external world becomes part of our inner world. In turn, the substantive element of the external world is reduced to a ceaseless flux and its fleeting, fragmentary and contradictory moments are all incorporated into our inner life.' (Frisby 1986: 46) According to Lukács, people are required to live within a huge socio-technical assemblage that appears to exist over their heads and against which subjectivity battles to assert itself: "Quality no longer matters. Quantity along decides everything" ... Thus time sheds its qualitative, variable, flowing nature; it freezes into an exactly delimited, quantifiable continuum filled with quantifiable 'things' (the reified, mechanically objectified 'performance' of the worker, wholly separated from his total human personality): in short, time becomes space. (Lukács 1968 [1922]: 90 \{emphasis added\}).

It is this evisceration of time's quality and its translation into a quantifiable medium that lies behind the crucial process of reification in which our prior notion of internal consciousness is increasingly difficult to distinguish from the reality that surrounds us. It also constitutes a significant point of agreement between otherwise radically opposed thinkers. It fits with: McLuhan's concept of electronic media as the outering of the human sensorium; the enthusiatic theorizing of the deterritorialized subject; and various novelists who are concerned about the existential consequences of such a process. Updating Simmel's account of modernity for the further speeded up context of contemporary fast capitalism, J. G. Ballard, for example, suggests that: 'In the past we have always assumed that the external work around us has represented reality, however confusing or uncertain, and that the inner world of our minds, its dreams, hopes, ambitions, represented the realm of fantasy and the imagination. These roles its seems to me have been reversed ... the one small node of reality left to us is inside our own heads.' (Ballard 1995:5). According to this latter perspective, literature is an important resource because it equips the otherwise denuded subject with the mental resources to realize when the apparently empowering flows of the desiring schizoid individual do in fact represent a social pattern based upon alienation and anomie.

\section{Psychoanalysis in reverse-people and places without qualities}

\footnotetext{
'The heart is a muscle,'... 'You "know" in your limbic brain. The seat of instinct. The mammalian brain. Deeper, wider beyond logic. That is where advertising works, not in the upstart cortex. What we think of as 'mind' is only a sort of jumped-up gland, piggybacking on the reptilian brainstem and the older, mammalian mind, but our culture tricks us into recognizing it as all of consciousness. The mammalian spreads continent-wide beneath it, mute and muscular, attending its ancient agenda. And makes us buy things ... When I founded Blue Ant, that was my core tenet, that all truly viable advertising addresses that older, deeper mind, beyond language and logic.' (Gibson 2003: 69)
}

Lowenthal described the culture industry as "psychoanalysis in reverse" meaning that instead of attempting to discover and cure our deepest neuroses and complexes, it uncovers only in order to massage them for the purposes of exploitation and commercial gain. Whilst Gibson's earlier work describes the plaisir experienced within capital's fast flows, it also heavily implies that authentically empowering again-jouissance is lacking. In addition to the druglike dependency Case (Neuromancer's cyberpunk protagonist) has for the Matrix, Dixie Flatline is a character who only consists of a disembodied perpetually online character. In Pattern Recognition, Gibson pays more explicit attention to this lack in relation to contemporary commodity culture. To the extent that flows have a determining meaning it is one dominated by the essentially existentially empty commodity form. For Gibson, information in fast capitalism serves to effect the process of psychoanalysis in reverse as effectively and subtly as possible. As one 
of his characters, Bigend, the head of a cutting-edge advertising agency puts it: 'I want to make the public aware of something they don't quite yet know that they know — or have them feel that way. Because they'll move on that, do you understand? They'll think they thought of it first. It's about transferring information, but at the same time about a certain lack of specificity.' (Gibson 2003: 63) In fast capitalism, what ultimately matters, is not an object's essential qualities but its position within a set of relations. This set of relations has evolved from Marx's notion of exchange-value to one of a highly sophisticated sign value that appeals, as we can see in the quotation above directly to the consumer's limbic id rather than any socially responsible superego. Gibson's fictional id-centred company, Blue Ant, is a corporate solution to Simmel and Ballard's inner/outer confusion premised upon the creation of an atmosphere that is nominally external to the human subject but which in practice appeals in a highly effective way to the subconscious. For example, the sexualized image of a woman is used in Pattern Recognition to entrap a hacker in a manner typical of the wider process of id-driven commodification: 'Bigend would recognize the image-toggle instantly, childlike innocence and hardboiled come-on alternating at some frequency beyond perception.' (Gibson 2003: 128) It is at points like this that the aesthetic function of literature comes into its own. Gibson describes here a felt experience beyond the bounds of conventional social science but none the less real for that.

In Kracauer's essay “The Hotel Lobby" (1995 [1963]), he highlights the atemporality of the hotel's artificially enclosed environment as a microcosm of the wider essential emptiness of a fast capitalism that redefines time in terms of the homogeneous spatial flows. In contrast to Deleuze and Guatarri's celebration of the schizoid personality, the lobby's denizens are dismissed as mannequins [4]. This fits with Lukács's conception of capitalism's reifying tendencies and its effect upon the decentred subject who becomes a cog in an overarching mechanical system (a process which exponentially speeds up with the advent of digitality). Such a system acts to: 'transform the basic categories of man's immediate attitude to the world: it reduces space and time to a common denominator and degrades time to the dimension of space. (Lukács 1968 [1922]: 89 \{emphasis added\}) There are a number of novelists from whom one can cull richly detailed examples of both the personality types and their physical environments produced within this reduction of time to space and its subsequent transformation of traditional human categories. In the archetypal flux-novel Transmission, Kunzru delineates the appositely named Guy Swift a character who, cosmocratically flying over communities of the dispossessed, is like the flâneur, he is in but not of society. Mirroring Cayce, the commodity cool-hunter from Pattern Recognition, Swift's comparative advantage is his preternatural sensitivity to the libidinal flows of fast capitalism to the extent that he feels that his relationship to the future is a personal one: 'In certain places_on moving walkways, at trade shows, in car showrooms-he felt it was physically connected to him, as through some unexplained mechanism futurity was feeding back into his body: an alien fibrillation, a flutter of potential'. (Kunzru 2004: 20) As such Guy Swift represents a powerful example of Eagleton's further development of Luckac's reified subject into the über-postmodern person:

With postmodernism, the will turns back upon itself and colonizes the strenuously willing subject itself. It gives birth to a human being every bit as protean and diffuse as the society around it. The creature who emerges from postmodern thought is centreless, hedonistic, self-inventing, ceaselessly adaptive ... Postmodernists oppose universality, and well they might; nothing is more parochial than the kind of human they admire ... The human subject finally breaks free of the restriction which is itself. If all that is solid must be dissolved into air, there can be no exceptions made for human beings. (Eagleton 2003:190)

This description appears extremely close to Deleuze and Guattari's notion of the schizoid individual. The main difference is perhaps the aesthetically-informed response such a character type produces. For celebrants of fast capitalism this is a figure to be aspired to, for critical theorists it is a disturbing, emptied-out, commodified caricature of what it is to be authentically human.

In Guy Swift we see the resulting invasive commercialization of the individual in the mix of New Age depthlessness with the amoral scientific application of the the limbic strategies preferred by Bigend: 'he had experienced what he described as a personal epiphany, the realization at a full moon party in Thailand that his future lay in the science of 'deep branding', the great quest to harness what ... he termed the 'emotional magma that wells from the core of planet brand'. (Kunzru 2004: 20). At the broader societal level, it is equally unclear from literature what advantages stem from the deterritorialization of the individual. In Baudrillard's take on fast capitalism, 'Astral America. The lyrical nature of pure circulation.' (Baudrillard 1988: 27), we encounter his notion of the aggregate version of the deterritorialized individual, the fatal masses: '...this going beyond the social, the irruption of the more social than social-the mass; this is a social that has absorbed all the inverse energies of the antisocial, of inertia, resistance and silence.' (Baudrillard 1990: 10). The corresponding literary aesthetic suggests that such a public: 
... is best visualized as a vicious, lazy, profoundly ignorant, perpetually hungry organism craving the warm god-flesh of the anointed. Personally I like to imagine something the size of a baby hippo, the color of a week-old boiled potato, that lives by itself, in the dark, in a double-wide on the outskirts of Topeka. It's covered with eyes and it sweats constantly. The sweat runs into those eyes and makes them sting. It has no mouth ... no genitals, and can only express its mute extremes of murderous rage and infantile desire by changing the channels on a universal remote. Or by voting in presidential elections. (Gibson 1996: 28-29)

Matching the death of the individual flâneur, such masses mark the death of the body politic paradoxically discussed, as it is, in gross physical terms redolent of fast capitalism's patrician, Guy Swift-like desire to stay above the seething masses.

Ballard's work consistently provides powerful descriptions of the sterile, decontextualized physical environments that are the corollary to the intensely felt personal immersion into informational flows by such contrasting figures as Guy Swift and Gibson's vividly literal couch potato. In Cocaine Nights, for example, his narrator describes travelling through the communities of the expatriate rich in southern Spain: 'I seemed to be moving through a zone that was fully accessible only to a neuroscientist, and scarcely at all to a travel writer. The white facades of the villas and apartment houses were like blocks of time that had crystallized beside the road. Here on the Costa del Sol nothing would ever happen again, and the people of the pueblos were already the ghosts of themselves.' (Ballard 1997: 75) Such ghosts need only 'that part of the external world that was distilled from the sky by their satellite dishes.' (Ballard 1997: 216) In society of flux: 'it's irritating to be reminded of the contingent world.' 'A drifting leaf? A passing rainshower? Bird shit on the sleeve?" "That sort of thing". (Ballard 2001: 19) The running tracks are 'manicured' (ibid: 18), 'the golf courses began to multiply like the symptoms of a hypertrophied grassland cancer". (Ballard 1997: 15) and, 'Over the immaculate gardens hung the air of well-bred catatonia that only money can buy'. (ibid:20) The sterility of such a lifeworld suggests that the desiring flows of fast capitalism are less organically carnivalesque than they might superficially appear:

\begin{abstract}
She's never actually seen soil emerge from any incision they might make in the street, here; it's as though there is nothing beneath the pavement but a clean, uniformly dense substrate of pipes and wiring. She walks on ... until she finds herself nearing Kabukicho, the all-night zone they call Sleepless Castle, its streets bright as day, very few surfaces lacking at least one highly active source of illumination ... the land of mahjong parlours ... sex shops, video porn ... but all of it managed with a Vegas-like sobriety of intent that makes her wonder how much fun any of it could really be, even for the committed enthusiast ... restless street-level facades seeming to form a single unbroken surface of neon carnival excess (Gibson 2003: 130-131)
\end{abstract}

The above examples suggest that we should be more sensitive to what our embracement of fast capitalism's flows implies for the state of our human qualities: 'The lack of something definite at the centre of the soul impels us to search for momentary satisfaction in ever-new stimulations, sensations and external activities. Thus it is that we become entangled in the instability and helplessness that manifests itself as the tumult of the metropolis' (cited in Frisby 1986: 72) Like the behind-the-scenes machinery and logistical scale of the 'spontaneous' fun of a theme park, the frantic flows of fast capitalism's carnival of excess belie the manufactured inner emptiness of their anomic hues of neon.

\title{
Time Squared
}

In the centers of night life the illumination is so harsh that one has to hold one's hands over one's ears. Meanwhile the lights have gathered for their own pleasure, instead of shining for man. Their glowing traces want to illuminate the night but succeed only in chasing it away. Their advertisements sink into the mind without allowing one to decipher them. The reddish gleam that lingers settles like a cloak over one's thoughts. (Kracauer 1995: 43)

As capitalism has matured, Baudelaire's reservoir of electricity has become less metaphorical and now appears across a wide timescale of literature that deals with the new atmosphere created in urban centres. Kracauer's above account owes something to Simmel's concepts of neurasthenia, Chokerlebnis and new blasé mental attitudes that urban dwellers need to adopt as a survival strategy for the qualitatively new social conditions created by mass living. In flux theory such practical accommodation has assumed an uncritical, celebratory bent so that seventy three years after Kracauer's essay, John Seabrook can describe with enjoyment how: 
The air was fuzzy with the weird yellow tornado light of Times Square by day, a blend of sunlight and wattage, the real and the mediated-the color of Buzz. Buzz is the collective stream of consciousness. William James's "buzzing confusion," objectified, a shapeless substance into which politics and gossip, art and pornography, virtue and money, the fame of heroes and the celebrity of murderers, all bleed. In Times Square you could see the Buzz that you felt going through your mind. I found it soothing just to stand there on my way to and from work and let the yellow light run into my synapses. In that moment the worlds outside and inside my skull became one. (Seabrook 2000: 5)

Seabrook's panegyric from his book Nobrow (so entitled to indicate how society has now supplanted high brow culture) provides an interesting contrast to Kracauer's work at various levels. Like Kracauer and Benjamin, he emphasizes the undermining of the real by the mediated (Benjamin's loss of aura and Kracauer's sense of the growing autonomy of mediated values over the original ones they supplant). The very name Times Square resonates with both Kracauer's conceptions of memory as a distinctly human category of non-mediated time and the strangely affective, Matrix-precursing town square Kracauer and Benjamin found together in Marseille and which the former nicknamed in their correspondence the "Place de l'Observance" [5] and which led Kracauer to describe how: 'once its observers have settled into their chairs, it expands toward the four sides of the world, overpowering the pitiful, soft, private parts of the dream: it is a square without mercy. [6]' (Kracauer 1995: 39) Seabrook, replaces Kracauer's concern with the overpowering, merciless, cerebrally invasive, of such squares with their "reddish gleam that lingers settles like a cloak over one's thoughts" with an uncritically enjoyable "buzz". For Kracauer, technology produces a heavily mediated "collective stream of consciousness" that replaces a 'liberated consciousness'. Rational understanding (vernunft) is fatally undermined by the perversion of reason embodied in the Ratio of the mass ornament of commodity society conveyed through such vehicles as photography's stream of contingent images, its "blizzard of photographs".

This new stream of unliberated, flux-ridden consumer consciousness is a common theme in cyberpunk's vivid portrayal of Kracauer's observations. Neil Stephenson's Snowcrash (1993), for example, provides the concept of the loglo which Stephenson describes in relation to the experience of a high-speed pizza-delivery man, the Deliverator ('a Type A driver with Rabies' [ibid: 7]) hurtling along a private freeway, CSV-5 thus: 'The loglo, overhead, marking out the CSV- 5 in twin contrails, is a body of electrical light made of innumerable cells, each cell designed in Manhattan by imageers ... Despite their efforts to stand out, they all smear together, especially at a hundred and twenty kilometres per hour.' (ibid: 7) Early in the novel Spares, the protagonist Randal describes how the the flux described in the above accounts of the neon aesthetic act invasively upon previously identifiable architectural structures serving to further blur the individual's sense of the distinction to be made between their inside/outside, and the $\mathrm{im} / \mathrm{material}$. He describes the huge oblong strucuture of a shopping complex (the MegaMall) that has successfully commodified the role previously played by cities: "I stared out at the points of light, the studs in the mind-fuckingly large expanse of wall. It still looked extraordinary, still said to me, as it always had, that I had to be inside it." (Smith 1996: 15) Faced with fast capitalism, flux theory risks aping Randal at his most uncritical and impressionable, to the extent that it engages with flux but, in its desire to enter it, loses its critical edge: 'Intellectual matters are no longer an ivory-tower affair, but belong to the world of media and shopping malls, bedrooms and brothels. As such, they rejoin everyday life-but only at the risk of losing their ability to subject it to critique.' (Eagleton 2003: 3).

In contrast, that critical distance is still possible for literature because of the ability of the aesthetic mode to address the $\mathrm{im} /$ material tension of the sensuous and the abstract. Gibson describes the technologically-mediated phenomenology of life on the street but does so with a sophisticated appreciation of the level of radicality to be found there. Gibson is thus lauded for his literary street credibility: 'Gibson puts an end to that ... white-bread technocrat in his ivory tower ... In Gibson's work we find ourselves in the streets and alleys, in a realm of sweaty, white-knuckled survival, where high tech is a constant subliminal hum, 'like a deranged experiment in social Darwinism, designed by a bored researcher who kept one thumb permanently on the fast-forward button.' (Sterling in Gibson 1988: 11). In his short story "Burning Chrome", a character describes how he is using a 'Vasopressin inhaler' to get high and that 'Clinically they use the stuff to counter senile amnesia, but the street finds its own uses for things.' (Gibson 1986: 215 [emphasis added]) This theme of the radical oppositional potential in any technology runs throughout Gibson's novels. It has been adopted more widely as a hacker motto and arguably informs some of the theoretical literature that seeks a positive, empowering potential in the technologies of fast capitalism.

Importantly, however, Gibson avoids the temptation over-valorize the street's ability to oppose fast capitalism's imperatives. Parallel to his sense of the street's oppositional ability to re-engineer technology, comes a sensitivity (frequently lacking in flux theories) to the ease with which such opposition is recuperated by fast capitalism. In Neuromancer, we have already seen how the flux of the urban environment is described as 'a deliberately unsupervised 
playground for technology itself.' (Gibson 1984: 19) Later in Pattern Recognition, this recuperation extends to the non-systemic elements of the street and its previous status as a place of relative respite from the remorseless spread of the commodity form: 'Cayce ... has been tracking the street-level emergence of what she thinks of as 'urban survival' footwear, and though this is so far at the level of consumer re-purposing, she has no doubt that commodification will soon follow identification'. (Gibson 2003: 9-10) In terms redolent of a military operation: 'She's been dropped into neighbourhoods like Dogtown, which birthed skateboarding, to explore roots in hope of finding whatever the next thing might be ... She's met the very Mexican who first wore his baseball cap backwards.' (Gibson 2003: 32). Gibson portrays a society in which inventive deviations from the commodified norm are tolerated only for as long as it takes to commodify such novelty.

\section{The Anomic Monadic Moment}

We may forget about totality, but totality, for good or ill, will not forget about us, even in our most microscopic meditations. If we can unpack the whole from the most humble particular, glimpse eternity in a grain of sand, this is because we inhabit a social order which tolerates particularity only as an obedient instantiation of the universal. We must no longer aim thought directly at this totality, but neither should we surrender ourselves to some pure play of difference, which would be quite as monotonous as the dreariest self-identity and indeed finally indistinguishable from it. (Eagleton 1990: 346)

Above, Eagleton describes Adorno's notion of the micrological immersion. This is an important alternative to the uncritical immersion of flux theory. In Gibson's previous account of the ultimate fate of street fashion we have seen how the social pattern of fast capitalism is one that 'tolerates particularity only as an obedient instantiation of the universal.' It is no surprise that critical figures like Adorno, Jameson and Eagleton who emphasize the importance of maintaining a focus upon the tension between the general and the particular, are not averse to using literature as a complement to their theory. This is because literature still has the power to steer us clear of identity thinking and show us the price to be paid for our contemporary accommodation with the systematizing totality of flux in terms of individual alienation and more general urban estrangement. In The Arcades Project (1999) Benjamin attempted to interpret phantasmagorical nature of capitalist reality more positively-in terms of a historical past. Here he saw the opportunities the weird and wonderful juxtaposition of commodities created for sudden explosive insights into the historical nature of a given moment in a process variously translated from the original German as a configuration or constellation. In his On the Concept of History, he highlights the weaknesses of a universal history (akin to flux theory) that lacks a: 'theoretical armature. Its procedure is additive; it musters a mass of data to fill the homogeneous, empty time.' (Benjamin 2003 [1940] 396) To compensate:

\footnotetext{
Materialistic historiography, on the other hand, is based on a constructive principle. Thinking involves not only the movement of thoughts, but their arrest as well. Where thinking suddenly comes to a stop in a constellation saturated with tensions, it gives that constellation a shock, by which thinking is crystallized as a monad. The historical materialist approaches a historical subject only where it confronts him as a monad. In this structure he recognizes the sign of a Messianic arrest of happening, or (to put it differently) a revolutionary chance in the fight for the oppressed past. He takes cognizance of it in order to blast a specific era out of the homogeneous course of history; thus, he blasts a specific life out of the era, a specific work out of the lifework. As a result of this method the lifework is both preserved and sublated in the work, the era in the lifework, and the entire course of history Min the era. The nourishing fruit of what is historically understood contains time in its interior as a precious but tasteless seed. (Benjamin 2003 [1940] Thesis XVII [original italics, emboldened emphasis added])
}

We can see here how amidst movement there is a need to seek an arrest of time so that it can be reduced to a human scale. The existential tension that human(e)ly experienced time contains between the past, present, and future of a moment needs to be reclaimed from the relentless rush of technological mediation. In his essay, "On Photography", Kracauer argues that:

In order for history to present itself, the mere surface coherence offered by photography must be destroyed. For in the artwork the meaning of the object takes on spatial appearance, whereas in photography the spatial appearance of an object is its meaning. The two spatial appearances-the "natural" one and that of the object permeated by cognition-are not identical ... The artwork, too, disintegrates over time; but its meaning arises out of its crumbled elements, whereas photography merely stockpiles the elements. (Kracauer 1995: 52)

Literature is arguably at its most useful as a corrective to flux theory when it focuses upon such crumbled 
elements. In Spares (1996), for example, the protagonist Randal stumbles across some children's tricycles only to find that they are permanent fixtures glued to the floor to provide residents of the Darwinian post-social Megamall with an object permeated by at least the trace of cognition in the form of fake nostalgia. Fast capitalism has moved on apace since Musil's Vienna and Gibson provides us with a suitably altered account that not only takes such exponentially increased speed into account. Set in a New York street near to the site and seconds before the 9-11 tragedy it provides a powerful example of a Benjaminian seed of time:

\begin{abstract}
She had watched a single petal fall, from a dead rose, in the tiny display window of an eccentric Spring Street dealer in antiques ... The dead roses, arranged in an off-white Fiestaware vase, appeared to have been there for several months. They would have been white, when fresh, but now looked like parchment ... the objects in the window seemed to change in accordance with some peculiar poetry of their own, and she was in the habit, usually, of pausing to look when she passed this way. The fall of the petal, and somewhere a crash, taken perhaps as some impact of large trucks, one of those unexplained events in the sonic backdrop of lower Manhattan. Leaving her sole witness to this minute fall. Perhaps there is a siren then or sirens, but there are always sirens, in New York. (Gibson 2003: 135-136)
\end{abstract}

Whether such an incident as this is described as a monadic moment, a constellation/configuration or a micrological immersion, Benjamin's hopes for a revelatory power have been reduced yet further from the site of Ballard's hypertrophied grassland cancer of golf-courses irrigated by capital to the contemplation of a single dead petal.

Cayce experiences Simmell and Ballard's previously cited ontological reversal of the conventional conceptualization of an inside/outside so that witnessing the 9-11 tragedy from a nearby towerblock becomes: 'like watching one of her own dreams on television. Some vast and deeply personal insult to any ordinary notion of interiority. An experience outside of culture.' (Gibson 2003: 137) The reified society of brands in which objects assume the status of social relations in contrast to people's objectified ones and to which Cayce has such an involuntary affinity, is, in this monadic moment, thrown into understated relief by a small collection of antique objects that as in Benjamin's arcades have retained 'some peculiar poetry of their own'. Instead of Musil's truck, this time we have just the mistaken impression that one has crashed. What has actually happened is that into the the urban illogicality of urban commodity culture has irrupted a much darker fundamentalism with its own conception of universal history. Thus, via his use of the aesthetic, Gibson demonstrates to us the catastrophic results of our social immersion in the logic-free neon sea that Kracauer previously identified as acting like a cloak over our thoughts: 'Looking up now into the manically animated forest of signs, she sees the Coca-Cola logo pulsing on a huge screen, high up on a building, followed by the slogan "NO REASON!" This vanishes, replaced by a news clip, dark-skinned men in bright robes. She blinks, imagining the towers burning there, framed amid image-flash and whirl. (Gibson 2003: 125) Whereas in The Dialectic of Enlightenment (1999 [1949]), Horkheimer and Adorno describe the mythological Sirens against whose temptations Odysseus is forced to bind himself to his ship's mast, here Cayce experiences immensely more mundane sirens. Representing the atrophied allure of the essentially empty, but nevertheless, stockpiled brand environment she douses for commercial purposes, these New York sirens merely act as unexplained events in a wider sonic backdrop. They serve to foreground the existential importance of a disintegrating rose. If not a lily of the field, Gibson's dessicated petal does at least provide a hint of Benjamin's 'Messianic cessation of happening'.

\title{
Conclusion-In Search of Lost Time
}

\begin{abstract}
Let Proust have his madeleines. We have ads. Some of my students are embarassed ... that cultural junk food is what they share ... Yet it is precisely the recognition of jingles and brand names, precisely what high culturists abhor, that links us as a culture. More than anything else this paper-thin familiarity is what gives Adcult its incredible reach and equally incredible shallowness. It is a culture without memory and hence without depth. (Twitchell 1996: 7)

Capitalism ... for all its crass materialism, is secretly allergic to matter. No individual object can fulfil its voracious appetite as it hunts its way restlessly from one to the other, dissolving each of them to nothing in doomed pursuit of its ultimate desire. For all its love affair with matter, in the shape of Tuscan villas and double brandies, capitalist society harbours a secret hatred of the stuff. It is a culture shot through with fantasy, idealist to its core, powered by a disembodied will which dreams of pounding Nature to pieces. It makes an idol out of matter, but cannot stomach the resistance it offers to its grandiose schemes. (Eagleton 2003: 165)
\end{abstract}

Twitchell's above rejection of memory and cultural depth is unusual for its forthright acceptance of the (il) logical cultural consequences of the shift that occurs in the social pattern of a society subjected to an unprecedented 
rise in the quantity of images and sounds to produce a qualitatively new cultural environment largely shorn of an authentic sense of time and substance. We have seen previously how Lukács highlights the translation of time into space and this is of a piece with Jameson's (1991) description of postmodern experience as involving the "waning of affect". Flux theory's tendency to uncritically celebrate capitalism's speed and ability to abstract from the particularity of a sensuality situated in a human-centred time suggests that it is intellectual defeatism masquerading as a realistic accommodation to the historical situation. From Eagleton's assessment of capitalism's allergy to matter we can see at least the hint of a more critical mode of resistance to fast capitalism based upon paying more precise attention to the significance of what matters. This is a task that is greatly aided by the literary aesthetic and its innate focus upon the tension between the sensuality of the particular and the abstractness of the totality. Despite its rhetorical calls to find new ways to live in fast capitalism, flux theory's worst feature is its tendency to glibly disregard the political significance of that human experience mired deep in the midst of time and matter. The literary aesthetic may often appear far removed from direct politics but this paper argues that it is an essential part of the political unconscious needed to help us find a grounded 'street' perspective that is not in thrall to fast capitalism and such beliefs as: 'Instability of identity is 'subversive' — a claim which it would be interesting to test out among the socially dumped and disregarded'. (Eagleton 2003: 16) This is a perspective either avoided by flux-theorists and Guy Swift alike or merely co-opted into their flows:'... the rich have mobility while the poor have locality. Or rather, the poor have locality until the rich get their hands on it.' (ibid: 22) Despite offering to leave the time-bound Proust with his madeleine, the attitudes flux theory adopts to time and matter means that, in terms of theories that apologize for fast capitalism, it still takes the biscuit.

\section{Endnotes}

1. According to William H. Gass's introduction to The Recognitions (page viii).

2. For an excellent discussion of the totality in the context of Marxism see Martin Jay's Marxism and Totality: The Adventures of a Concept from Lukács to Habermas (1986).

3. For a full discussion of the dividual in this context see Williams Volume 1.1.

4. In his essay "Photography", Kracauer describes how the face of their grandmother as a young girl appears to her grandchildren "The smiles of mannequins in beauty parlors are just as rigid and perpetual” (1995:48), whilst in "The Hotel Lobby" he describes its denizens thus: "Remnants of individuals slip into the nirvana of relaxation, faces disappear behind newspapers, and the artificial continuous light illuminates nothing but mannequins" (ibid:183).

5. See Levin's footnote 1 pg 354 in Kracauer (1995)

6. This is a prescient and cogent description of the pervasive reach of bio-politics in such new forms as Reality TV.

\section{References}

Adorno, T. and Horkheimer, M. (1999 [1944]) The Dialectic of Enlightenment. London: Verso.

Ballard, J.G. (1995) Crash. London: Vintage.

----. (1997) Cocaine Nights. London: Flamingo.

-.--. (2001) Super-Cannes.London: Flamingo.

Baudelaire, C. (2003 [1859]) The Painter of Modern Life and Other Essays. London: Phaidon Press.

Baudrillard, J. (1988) The Ecstasy of Communication, trans. B. and C. Schutze, New York, NY: Semiotext(e).

---. (1990) Fatal Strategies. Translated by. P. Beitchman and W.G.J. Niesluchowski, New York/London: Semiotext(e)/ Pluto.
----. (2005) The Conspiracy of Art. Edited by Sylvere Lotringer and translated by Ames Hodges. New York, NY: Semiotext(e). Bauman, Z. (2000) Liquid Modernity.Cambridge: Polity. Benjamin, W. (1935) "The Work of Art in the Age of Mechanical Reproduction.” http://bid.berkeley.edu/bidclass/readings/ benjamin.html. Accessed May 15th 2005.

---- (1999) The Arcades Project. London: Harvard University Press.

---.. (2003) Selected Writings Volume 4 - 1938-40. Translated by Edmund Jephcott and Others, Edited by Howard Eiland and Michael W. Jennings. Cambridge Mass.: Harvard University Press. 
Deleuze, Gilles. 1992. Postscript on the Societies of Control October, 59: 3-7. http://www.spunk.org/texts/misc/ sp000962.txt. Accessed May 15, 2006.

Dostoyevsky, F. (2004 [1864]) Notes From the Underground. London: Everyman's Library.

Eagleton, T. (1990) The Ideology of the Aesthetic. London: Blackwell.

----. (2003) After Theory. London: Penguin Books.

Ferguson, P.P. (1994) "The flâneur on and off the streets of Paris". in K. Tester (ed.) The Flâneur. London: Routledge, pp. 22-42.

Foucault, M (1998) The History of Sexuality: The Will to Knowledge Vol 1. London: Penguin Books.

Frisby, D. (1986) Fragments of Modernity: theories of modernity in the work of Simmel, Kracauer and Benjamin. Cambridge, MA: MIT Press.

Gaddis, W. (1993 [1955]) The Recognitions. London: Penguin Books.

----. (2003 [1976]) JR. London: Atlantic Books.

----. (2005 [2002]) Agape, Agape. London: Atlantic Books.

Gibson, W. (1984) Neuromancer. London: Grafton.

-.-..(1986) Count Zero. London: Grafton.

----.(1988) Mona Lisa Overdrive. London: Grafton.

-.--. (2003) Pattern Recognition. London: Penguin.

Goldman, R. Papson,S. Kersey, N. “Speed: Through, Across, and In - The Landscapes of Capital”. Fast Capitalism. Vol 1.1.

Hardt, M. and Negri, A. (2000) Empire. Harvard, MA: Harvard University Press.

Hardt, M. and Negri, A. (2005) Multitude. London: Hamish Hamilton.

Harris, J. and Taylor, P.A. (2005) "Hacktivism." in H. Bidgoli (ed.) The Handbook of Information Security. Hoboken, NJ John Wiley.

Heidegger, M. (1977) The Question Concerning Technology and Other Essays. Translated by W.Lovitt, New York: Harper and Row.

Jameson, F. (1991) Postmodernism: The Cultural Logic of Late Capitalism. Durham, NC: Duke University Press.

Jay, M. (1986) Marxism and Totality: The adventures of a concept from Lukács to Habermas. Berkeley: University of California Press.

Jenks, C. (1995) "Watching Your Step: The History and Practice of the Flaneur" in Visual Culture. Ed. Chris Jenks, London: Routledge.

Kracauer, S. (1995 [1963]) "Photography" in T.Y. Levin (ed.) The Mass Ornament: Weimar Essays. Cambridge Mass. Harvard University Press.

Johnston, J. (1990) Carnival of Repetition: Gaddis's The Recognitions and Postmodern Theory. University of Pennsylvania Press, Philadelphia.

Jonsson, S. (2000) Subject Without Nation: Robert Musil And The History Of Modern Identity. London: Duke University Press.
Kittler, F.A. (1997) Literature Media, Information Systems. Edited by J. Johnston, Amsterdam: Overseas Publishers Association.

Kunzru, H. (2004) Transmission. London: Hamish Hamilton.

Lash, S. (2002) Critique of Information. London: Sage.

Leadbetter, C. (2000) Living on Thin Air: the new economy. London: Penguin.

Lukács, G. (1968 [1922]) "Reification and the consciousness of the proletariat". in History and Class Consciousness. London: Merlin Press.

Luke,Timothy W. "Politics and Self in the Age of Digital Re(pro) ducibility." Fast Capitalism Vol 1.1.

Marcuse, H. (2002 [1964]) One-Dimensional Man: Studies in the Ideology of Advanced Industrial Capitalism. London: Routledge.

McLuhan, M. (1995) [1964] Understanding Media. London: Routledge.

Moos, M. (ed.) (1997) Media Research: technology, art, communication. Amsterdam: Overseas Publishers Association.

Morse, M. (1998) Virtualities: television, media art, and cyberculture. Indianapolis: Indiana University Press.

Musil, R. (1979 [1930]) The Man without Qualities. Vol. 1, London: Picador.

Poe, E. A. (1992 [1850]) “The Man of the Crowd” in Edgar Allan Poe: The Complete Stories. London: Everyman's Library.

Ross, A. (1991) Strange Weather: Culture, Science, and Technology in the Age of Limits. London: Verso.

Seabrook, J. (2000) Nobrow: The Culture of Marketing and the Marketing of Culture. London: Methuen.

Smith, M.M. (1996) Spares. London: HarperCollins.

Stephenson, N. (1992) Snow Crash. New York, NY: RoC.

Taylor, P.A. (1998) Hackers: cyberpunks or microserfs? In Information, Communication and Society. 1(4): 401-19.

-.-. (1999) Hackers: crime in the digital sublime. London: Routledge.

-..-. (2001) Informational Intimacy \& Futuristic Flu: Love \& Confusion in the Matrix. In Information, Communication and Society 4:1 74-94.

-.-. (2005) From hackers to hacktivists: speed bumps on the global superhighway? In New Media \& Society. Vol7(5): 625-646.

Taylor, P. A. \& Harris, J. Ll. (2005) Digital Matters: Theory and Culture of the Matrix. London: Routledge.

Tester, K. (1994) [ed.] The Flâneur. London: Routledge.

Twitchell, J. B. (1996) AdcultUSA: The Triumph of Advertising in American Culture. New York: Colombia University Press.

Williams, Robert W. "Scanning Fast Capitalism: Quasipolitan Order and New Social Flowmations." In Fast Capitalism Vol 1.1 .

Žižek, S. 2004. Organs without Bodies: On Deleuze and Consequences. London: Routledge. 